\title{
Intracranial haemorrhage in infective endocarditis
}

Hémorragie intracrânienne dans l'endocardite infectieuse

\author{
Erwan Salaun $^{\mathrm{a}, *}$, Anissa Touil ${ }^{\mathrm{a}}$, Sandrine Hubert ${ }^{\mathrm{a}, \mathrm{b}}$, \\ Jean-Paul Casalta ${ }^{a, b}$, Frédérique Gouriet ${ }^{a, b}$, \\ Emmanuelle Robinet-Borgomano ${ }^{c}$, Emilie Doche ${ }^{c}$, \\ Nadia Laksiri ${ }^{c}$, Caroline Rey ${ }^{c}$, Cécile Lavoute ${ }^{a}$, \\ Sébastien Renard ${ }^{a}$, Hervé Brunel ${ }^{d}$, \\ Anne-Claire Casalta ${ }^{a}$, Julie Pradier ${ }^{a}$, \\ Jean-François Avierinos ${ }^{a}$, Hubert Lepidi ${ }^{a, b}$, \\ Laurence Camoin-Jau ${ }^{\text {b,e }}$, Alberto Riberi ${ }^{a, b}$, \\ Didier Raoult ${ }^{\mathrm{b}}$, Gilbert Habib ${ }^{\mathrm{a}, \mathrm{b}}$
}

\footnotetext{
a Cardiology Department, la Timone Hospital, AP-HM, boulevard Jean-Moulin, 13005 Marseille, France

b MEPHI, IRD, IHU-Méditerranée Infection, Aix Marseille University, AP-HM, 13005 Marseille, France

c Neurology Department, la Timone Hospital, AP-HM, 13005 Marseille, France

d Radiology Department, la Timone Hospital, AP-HM, 13005 Marseille, France

e Department of Hematology, Aix Marseille University, la Timone Hospital, AP-HM, 13005 Marseille, France
}

\section{KEYWORDS}

Infective endocarditis; Intracranial haemorrhage;
Received 13 December 2017; received in revised form 23 January 2018; accepted 16 March 2018 Available online 5 June 2018

\section{Summary}

Background. - Although intracranial cerebral haemorrhage $(\mathrm{ICH})$ complicating infective endocarditis (IE) is a critical clinical issue, its characteristics, impact, and prognosis remain poorly known.

Aims. - To assess the incidence, mechanisms, risk factors and prognosis of ICH complicating left-sided IE.

Abbreviations: $\mathrm{ICH}$, intracranial cerebral haemorrhage; IE, infective endocarditis; TOE, transoesophageal echocardiography; TTE, transthoracic echocardiography.

* Corresponding author.

E-mail address: salaun.er@gmail.com (E. Salaun). 


\section{Mycotic aneurysm; Neurological complication; Cerebral bleeding}

Methods. - In this single-centre study, 963 patients with possible or definite left-sided IE were included from January 2000 to December 2015.

Results. - Sixty-eight (7\%) patients had an ICH (mean age $57 \pm 13$ years; $75 \%$ male). ICH was classified into three groups according to mechanism: ruptured mycotic aneurysm $(n=22 ; 32 \%)$; haemorrhage after ischaemic stroke ( $n=27 ; 40 \%)$; and undetermined aetiology $(n=19 ; 28 \%)$. Five variables were independently associated with $\mathrm{ICH}$ : platelet count $<150 \times 10^{9} / \mathrm{L}$ (odds ratio [OR] 2.3, 95\% confidence interval $[\mathrm{Cl}] 1.01-5.4 ; P=0.049)$; severe valve regurgitation $(\mathrm{OR} 3.2$, 95\% Cl 1.3-7.6; $P=0.008)$; ischaemic stroke (OR 4.2, 95\% Cl 1.9-9.4; $P<0.001)$; other symptomatic systemic embolism (OR 14.1, 95\% Cl 5.1-38.9; $P<0.001)$; and presence of mycotic aneurysm (OR 100.2, 95\% Cl 29.2-343.7; $P<0.001)$. Overall, $237(24.6 \%)$ patients died within $2.3(0.7-10.4)$ months of follow-up. ICH was not associated with increased mortality $(P$ not significant). However, the 1-year mortality rate differed according to ICH mechanism: $14 \%, 15 \%$ and $45 \%$ in patients with ruptured mycotic aneurysm, haemorrhage after ischaemic stroke and undetermined aetiology, respectively $(P=0.03)$. In patients with an $\mathrm{ICH}$, mortality was higher in non-operated versus operated patients when cardiac surgery was indicated $(P=0.005)$. No operated patient had neurological deterioration.

Conclusions. - ICH is a common complication of left-sided IE. The impact on prognosis is dependent on mechanism (haemorrhage of undetermined aetiology). We observed a higher mortality rate in patients who had conservative treatment when cardiac surgery was indicated compared with in those who underwent cardiac surgery.

(c) 2018 Elsevier Masson SAS. All rights reserved.

\section{MOTS CLÉS \\ Endocardite infectieuse ; Hémorragie intracrânienne ; Anévrysme mycotique ; Complication neurologique ; Saignement cérébral}

\begin{abstract}
Résumé
Contexte. - Les hémorragies intracrâniennes (HIC) compliquant les endocarditis infectieuses (EI) sont une situation clinique cruciale, cependant leurs caractéristiques, impacts, et pronostic restent mal connus.

Objectifs. - Analyser l'incidence, les mécanismes, les facteurs de risque, et le pronostic des HIC compliquant les El.

Méthodes. - Cette étude monocentrique a inclus 963 patients avec une El du cœur gauche possible ou certaine entre janvier 2000 et décembre 2015.

Résultats. - Soixante-huit (7\%) présentaient une HIC (âge moyen de $57 \pm 13$ ans et $75 \%$ d'hommes). L'HIC était classée selon trois mécanismes : rupture d'anévrysme mycotique $(n=22$, $32 \%$ ) patients, hémorragie secondaire à un accident ischémique cérébral ( $n=27,40 \%)$, étiologie non déterminée $(n=19,28 \%)$. Cinq paramètres étaient associés à l'HIC : thrombopénie (OR $2,3$, IC $95 \% 1,01-5,4 ; p=0,049)$, fuite sévère valvulaire (OR 3,2, IC $95 \% 1,3-7,6 ; p=0,008$ ), accident ischémique cérébral (OR 4,2, IC $95 \% 1,9-9,4 ; p<0,001)$, autre embolie systémique symptomatique (OR 14,1, IC $95 \% 5,1-38,9 ; p<0,001)$, et la présence d'un anévrysme mycotique (OR 100,2, IC $95 \%$ 29,2-343,7; $p<0,001)$. La présence d'une HIC n'était pas associée à une surmortalité $(p=N S)$. Cependant, le taux de décès à un an était différent selon le mécanisme : $14 \%, 15 \%$ et $45 \%$ respectivement en cas de rupture d'anévrysme mycotique, hémorragie secondaire à un accident ischémique cérébral, et d'étiologie indéterminée $(p=0,03)$. Chez les patients présentant une HIC, la mortalité était plus élevée avec un traitement conservateur malgré l'indication de chirurgie cardiaque par rapport à ceux qui en bénéficiaient $(p=0,005)$. Aucune détérioration neurologique n'est survenue chez les patients ayant bénéficiés d'une chirurgie cardiaque.

Conclusions. - L'HIC représente une complication commune aux El. L'impact pronostique est dépendant du mécanisme de l'HIC (étiologie indéterminée). Nous observons une surmortalité en cas de traitement conservateur lorsqu'il existe une indication chirurgicale cardiaque.

(c) 2018 Elsevier Masson SAS. Tous droits réservés.
\end{abstract}

complications [1,2]. Neurological complications related to IE are multiple (ischaemic, haemorrhagic, infective), occur in $17-82 \%$ of patients with left-sided IE $[3,4]$ and are globally associated with an excess of mortality [5]. However,
Infective endocarditis (IE) is a complex and deadly disease, which associates cardiac infective location and multiorgan 


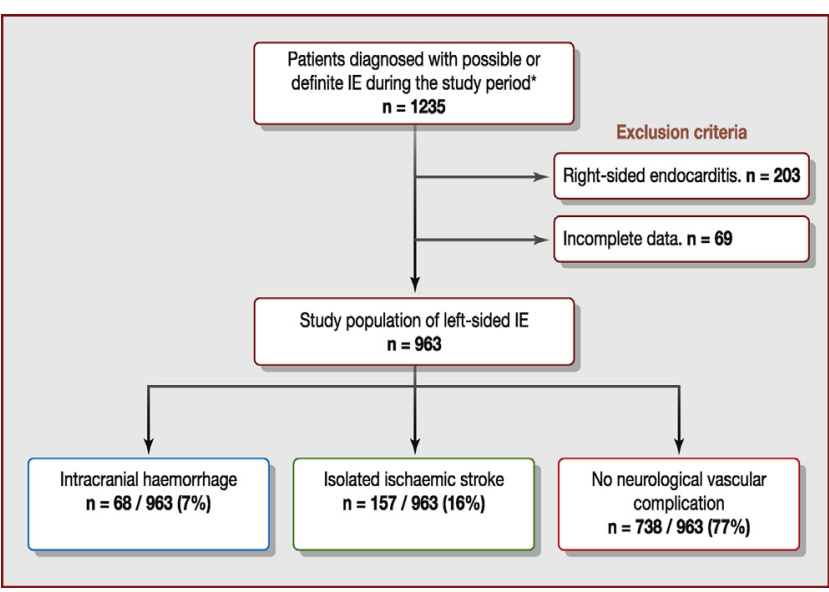

Figure 1. Study flow chart. IE: infective endocarditis. * The diagnosis of infective endocarditis was established according to the modified Duke criteria by the endocarditis team for each patient, and during the period from January 2000 to December 2015.

different types of neurological complications and their presentation may affect the clinical course of IE differently $[6,7]$. The impact of ischaemic stroke is well known $[5,7]$, and clear recommendations exist concerning the management of ischaemic lesions [1]. Conversely, the impact of intracranial cerebral haemorrhage $(\mathrm{ICH})$ and the resulting management is less described [1]. Moreover, several mechanisms may lead to ICH during IE [6,7], and no large study has described the characteristics of these different lesions and their impact.

Our objectives were to assess the incidence and mechanisms of ICH in patients with left-sided IE, the risk factors for its development, the associated risk of death and the management of patients after $\mathrm{ICH}$.

\section{Methods}

\section{Inclusion criteria}

This study included patients consecutively diagnosed with possible or definite IE, according to the modified Duke criteria [8], in a single-centre, and who were registered in a dedicated database between January 2000 and December $2015(n=1235)$. The exclusion criteria were right-sided IE $(n=203)$ and incomplete data $(n=69)$ (Fig. 1). Written informed consent was obtained from all participating patients, as required by the institutional review board under an approved protocol. Blood cultures, serological assessment, transthoracic echocardiography (TTE) and transoesophageal echocardiography (TOE) were performed systematically within 48 hours of admission. A cerebral computed tomography scan was performed on admission, and was repeated if indicated clinically. Complementary cerebral imaging (cerebral magnetic resonance imaging and catheter-based cerebral angiography) was performed depending on the neurological presentation, and after advice from neurological specialists and the endocarditis team, including the cardiologists, the cardiac surgeons and the infectious disease specialist.

\section{Clinical and echocardiographic data}

The following criteria were collected prospectively: age; sex; previous valve surgery (mechanical valve or bioprosthetic valve/homograft/valve repair); intravenous drug abuse; diabetes; hypertension; history of atrial fibrillation; coronary artery disease; history of ischaemic stroke; Charlson Index score; oral anticoagulant or platelet inhibition therapies; creatinine serum concentration; haemoglobin concentration; platelet count; C-reactive protein serum concentration; and symptomatic systemic embolism other than cerebral.

TTE and TOE were performed as reported previously [9]. Echocardiographic data included presence of vegetation and periannular lesion (defined as the presence of abscess and/or pseudoaneurysm and/or fistula) [1]. The vegetation length was measured in various planes, and the maximal length was used. Valvular regurgitations were quantified following current recommendations $[10,11]$.

\section{Definitions}

Neurological vascular complications were classified into two categories: isolated ischaemic stroke; and $\mathrm{ICH}$. An experienced neurological specialist confirmed the diagnosis of all neurological vascular complications. Isolated ischaemic stroke (i.e. with no sign of cerebral haemorrhage) included ischaemic stroke with a persistent deficit, transient ischaemic attack and silent cerebral embolism considered as recent on cerebral imaging. Ischaemic stroke with a persistent deficit was defined as the persistence for $>24$ hours of a focal neurologic deficit caused by altered circulation of the cerebral hemispheres, brain stem or cerebellum. Transient ischaemic attack was defined as focal neurological symptoms of sudden occurrence and rapid resolution ( $<24$ hours), related to altered circulation of the brain. Silent cerebral embolism was detected by cerebral imaging performed after admission. The mechanism of $\mathrm{ICH}$ was established by expert consensus between the neurologist and neuroradiologist after clinical and imaging examinations, and ICH was classified as: $\mathrm{ICH}$ secondary to ruptured mycotic aneurysm; haemorrhage after an acute ischaemic stroke; and ICH of undetermined aetiology.

Haemorrhage after an acute ischaemic stroke was defined by both chronological and imaging criteria. Undetermined aetiology included necrotic vessel aetiology and/or undiagnosed other lesion in the imaging assessment. Management of the neurological vascular complication was performed according to the guidelines [12,13]. As microbleeds have not been associated with $\mathrm{ICH}$ and postoperative neurological complications in the literature [1], the presence of microbleeds was not considered in our study (also because cerebral magnetic resonance imaging was not performed in all patients).

\section{Indication for cardiac surgery}

The indication for cardiac surgery was based on the guidelines for the management of IE $[1,14,15]$, in patients with high-risk features. The three main indications were heart failure, uncontrolled infection and prevention of 
embolic events. The final decision to perform cardiac surgery was made by the endocarditis team, in agreement with the neuroradiologists, neurologists and neurosurgeons. When cardiac surgery was performed, the timing was dichotomized according to the period of antibiotic therapy (i.e. during or after the active phase of the antibiotic therapy) or displayed according to the delay with $\mathrm{ICH}$.

\section{Mortality and follow-up}

The primary endpoint was death from any cause during the follow-up. The secondary endpoints were: death immediately related to $\mathrm{ICH}$, defined by death as a result of neurological failure a few hours after the $\mathrm{ICH}$; and neurological deterioration after cardiac surgery in patients with an $\mathrm{ICH}$, defined by clinical neurological deterioration and/or worsening of the $\mathrm{ICH}$ and/or new $\mathrm{ICH}$. Follow-up information was obtained during and after the hospitalization, with scheduled visits at 1 month, 3 months, 6 months and 1 year. If a patient missed a scheduled visit, supplemental followup information was obtained by contacting the patient or the patient's physicians.

\section{Statistical analysis}

Continuous data are expressed as means \pm standard deviations or medians [interquartile ranges], and were compared with analysis of variance and Tukey's range test. Categorical data are expressed as numbers and percentages, and were compared by use of the $\chi^{2}$ test or Fisher's exact test. Time-to-event curves were obtained by the KaplanMeier method, and were compared with the log-rank test. The Cox proportional hazards model was used to calculate adjusted hazard ratios and their 95\% confidence intervals (Cls). The final model included clinically relevant variables and/or variables with a $P$-value $<0.10$ in the univariate analysis. The multivariable Cox model to predict midterm mortality included: age; sex; diabetes; hypertension; coronary disease; history of cardiac surgery; creatinine serum concentration; ischaemic stroke; ICH; length of vegetation; periannular lesion; severe regurgitation; and cardiac surgery for IE during the first year. An exploratory multivariable analysis by logistic regression was performed to evaluate the predictors of $\mathrm{ICH}$. The final model included clinically relevant variables and/or variables with a $P$-value $<0.10$ in the univariate analysis. The results are reported as adjusted odds ratios (ORs) with associated $95 \% \mathrm{Cls}$. A value of $P<0.05$ was considered statistically significant. Statistical analysis was performed using JMP software, version 13 (SAS Institute, Cary, NC, USA).

\section{Results}

\section{Neurological vascular complications and patient characteristics}

Among the 963 patients with left-sided IE included in the study, 68 (7\%) had an ICH, 157 (16\%) had an isolated ischaemic stroke and 738 (77\%) had no neurological vascular complications. Baseline patient features are reported in Table 1 for patients with an $\mathrm{ICH}$, patients with an isolated ischaemic stroke and patients with no neurological vascular complications. Patients with an ICH had a mean age of $57 \pm 13$ years, and $75 \%$ were male; they were younger than patients with no neurological vascular complications, and had a higher rate of intravenous drug abuse than patients with isolated ischaemic stroke and those with no neurological vascular complications. Diabetes occurred significantly more frequently in patients with isolated ischaemic stroke.

Echocardiographic findings were similar, except for a higher rate of vegetation in the $\mathrm{ICH}$ and isolated ischaemic stroke groups, with longer vegetation in the isolated ischaemic stroke group than in patients with no neurological vascular complications. A higher rate of severe valve regurgitation was observed in the $\mathrm{ICH}$ group. Staphylococci were more frequent in patients with an $\mathrm{ICH}$ or isolated ischaemic stroke than in patients with no neurological vascular complications. Patients with an $\mathrm{ICH}$ had a higher rate of other symptomatic systemic embolisms and mycotic aneurysm. No relationship was observed between the occurrence of any neurological vascular complication and the use of antithrombotic therapy.

\section{Mechanisms of $\mathrm{ICH}$, and patient characteristics} Among patients with an $\mathrm{ICH}, 19(28 \%)$ had undetermined aetiology, 22 (32\%) had ruptured mycotic aneurysm and 27 (40\%) had haemorrhage after ischaemic stroke. Patients with ruptured mycotic aneurysm were younger $(51.5 \pm 2.7$ years; $P=0.03)$ and more frequently male $(n=21,95 \%$ male; $P=0.001)$ than those with haemorrhage after ischaemic stroke $(57.8 \pm 2.4$ years; $52 \%$ male, $n=14)$ and ICH of undetermined aetiology $(61.9 \pm 2.8$ years; $84 \%$ male, $n=16)$. Rates of intravenous drug abuse were similar in patients with haemorrhage after ischaemic stroke (15\%), ICH of undetermined aetiology (16\%) and ruptured mycotic aneurysm (18\%) ( $P$ not significant). Other history variables were also not significantly different between the three types of $\mathrm{ICH}$; these included diabetes, hypertension, history of atrial fibrillation, coronary disease, history of ischaemic stroke, Charlson Index score, oral anticoagulant therapy, platelet inhibition therapy and presence and type of previous cardiac surgery ( $P$ not significant for all).

Regarding cerebral imaging, lesions of ischaemic stroke were found concomitantly in five patients with an ICH of undetermined aetiology and in four patients with ruptured mycotic aneurysm. Five patients with haemorrhage after ischaemic stroke had unruptured mycotic aneurysm.

The location and severity of cardiac lesions were not significantly different according to the mechanism of $\mathrm{ICH}$, including valve location, periannular lesion, severe regurgitation and presence or length of vegetation ( $P$ not significant for all). Patients with ruptured mycotic aneurysm had more streptococci $(n=13,59 \% ; P=0.03)$ than others (seven patients [37\%] with an ICH of undetermined aetiology; six patients [22\%] with haemorrhage after ischaemic stroke). The rates of staphylococci, enterococci and other biological variables were not significantly different according to the mechanism of ICH ( $P$ not significant for all). Table 2 shows clinical signs, timing and methods of diagnosis for each mechanism of $\mathrm{ICH}$. 
Table 1 Comparison of patients with intracranial cerebral haemorrhage, ischaemic stroke or with no neurological vascular complication.

\begin{tabular}{|c|c|c|c|c|}
\hline Variables & $\begin{array}{l}\mathrm{ICH} \\
(n=68)\end{array}$ & $\begin{array}{l}\text { Isolated ischaemic } \\
\text { stroke } \\
(n=157)\end{array}$ & $\begin{array}{l}\text { No neurological } \\
\text { complication } \\
(n=738)\end{array}$ & $P^{a}$ \\
\hline \multicolumn{5}{|l|}{ Demographics and medical status } \\
\hline Age, (years) & $57 \pm 13^{b}$ & $61 \pm 18$ & $64 \pm 15$ & $<0.001$ \\
\hline Male & $51(75)$ & $110(70)$ & $529(72)$ & 0.8 \\
\hline Diabetes & $13(19)$ & $36(23)^{c}$ & $106(14)$ & 0.02 \\
\hline Arterial hypertension & $21(31)$ & $42(27)$ & $224(30)$ & 0.7 \\
\hline Coronary disease & $7(10)$ & $17(11)$ & $69(9)$ & 0.8 \\
\hline History of ischaemic stroke & $1(1.5)$ & $10(6)$ & 37 (5) & 0.3 \\
\hline Intravenous drug abuse & $11(16)^{d}$ & $9(6)$ & $55(7)$ & 0.02 \\
\hline History of atrial fibrillation & $18(27)$ & $36(23)$ & $154(21)$ & 0.5 \\
\hline Previous valve surgery & $18(27)$ & $46(30)$ & $227(31)$ & 0.7 \\
\hline Mechanical valve & $5(7.5)$ & $11(7)$ & $72(10)$ & 0.5 \\
\hline $\begin{array}{l}\text { Bioprosthetic valve/homograft/valve } \\
\text { repair }\end{array}$ & $13(19)$ & $35(23)$ & $160(22)$ & 0.7 \\
\hline Anticoagulant therapy & $18(27)$ & $34(22)$ & $175(24)$ & 0.7 \\
\hline Platelet inhibition therapy & $12(18)$ & $28(18)$ & 140 (19) & 0.9 \\
\hline Charlson Index score & $3[1-4]$ & $3[2-5]$ & $3[1-5]$ & 0.9 \\
\hline \multicolumn{5}{|l|}{ Echocardiographic findings } \\
\hline Affected valve & & & & 0.5 \\
\hline Aortic & $35(51)$ & $63(40)$ & $324(44)$ & \\
\hline Mitral & $22(32)$ & $61(39)$ & $256(35)$ & \\
\hline Aortic and mitral & $11(16)$ & 30 (19) & $116(16)$ & \\
\hline Vegetation & $59(87)^{b}$ & $134(85.5)^{c}$ & $534(73)$ & $<0.001$ \\
\hline Vegetation length $(\mathrm{mm})$ & $14[8-20]$ & $15[10-19]^{\mathrm{c}}$ & $12[8-17]$ & $<0.01$ \\
\hline Periannular lesion & $22(32)$ & $51(32.5)$ & $199(27)$ & 0.3 \\
\hline Severe regurgitation & $53(78)^{d}$ & $61(39)$ & $253(34)$ & $<0.001$ \\
\hline Left ventricular ejection fraction (\%) & $62[60-65]^{\mathrm{b}}$ & $60[55-65]$ & $60[55-65]$ & 0.045 \\
\hline \multicolumn{5}{|l|}{ Biological findings } \\
\hline Haemoglobin $(\mathrm{g} / \mathrm{dL})$ & $10.2[0.94-12]$ & $10.8[0.98-12]$ & $10.8[0.96-12]$ & 0.4 \\
\hline Platelet count $\left(10^{9} / \mathrm{L}\right)$ & $220[141-308]$ & $246[153-317]$ & $252[171-332]$ & 0.2 \\
\hline $\begin{array}{l}\text { C-reactive protein serum } \\
\text { concentration }(\mathrm{mg} / \mathrm{L})\end{array}$ & $73[(37-179]$ & $109\left[(53-182]^{c}\right.$ & $71[31-136]$ & $<0.001$ \\
\hline $\begin{array}{l}\text { Creatinine serum concentration } \\
(\mu \mathrm{mol} / \mathrm{L})\end{array}$ & $86[71-130]$ & $86[73-138]$ & $95[76-140]$ & 0.2 \\
\hline \multicolumn{5}{|l|}{ Microbiological findings } \\
\hline Positive blood culture & $64(94)^{b}$ & $134(85.5)$ & $596(81)$ & 0.01 \\
\hline Staphylococci & $25(37)^{b}$ & $57(36)^{c}$ & $165(22)$ & $<0.001$ \\
\hline Streptococci & $26(38)$ & $42(27)$ & $225(30)$ & 0.2 \\
\hline Enterococci & $8(12)$ & $23(14.5)$ & $103(14)$ & 0.8 \\
\hline \multicolumn{5}{|l|}{ Complications and surgery } \\
\hline Other symptomatic systemic embolism & $25(37)^{d}$ & $5(3)$ & $23(3)$ & $<0.001$ \\
\hline Cerebral mycotic aneurysm & $27(40)^{d}$ & $5(3)^{c}$ & $2(0.3)$ & $<0.001$ \\
\hline Indication for cardiac surgery & $60(88)$ & $129(82)$ & $593(80)$ & 0.1 \\
\hline Cardiac surgery & $38(63)$ & 95 (74) & $433(73)$ & 0.4 \\
\hline $\begin{array}{l}\text { Cardiac surgery during versus after the } \\
\text { active phase }\end{array}$ & & & & $<0.001$ \\
\hline "During the active phase" $f$ & $21(55)^{d}$ & $87(91)$ & $376(87)$ & \\
\hline "After the active phase" $f$ & $17(44)^{\mathrm{d}}$ & $8(9)$ & $57(13)$ & \\
\hline
\end{tabular}

Data are expressed as mean \pm standard deviation, number (\%) or median [interquartile range]. ICH: intracranial cerebral haemorrhage.

a $P$-value for the comparison between the three groups of patients.

b $\mathrm{P}<0.05$ for "ICH" versus "no neurological complication".

c $\mathrm{P}<0.05$ for "ischaemic stroke" versus "no neurological complication".

d $\mathrm{P}<0.05$ for "ICH" versus "ischaemic stroke" and versus "no neurological complication".

e Percentages calculated among patients with indications of cardiac surgery.

$\mathrm{f}$ Percentages calculated among patients who underwent cardiac surgery. 
Table 2 Clinical signs, timing and methods of diagnosis according to the type of intracranial cerebral haemorrhage.

\begin{tabular}{|c|c|c|c|c|}
\hline Variables & $\begin{array}{l}\text { Undetermined } \\
\text { aetiology } \\
(n=19)\end{array}$ & $\begin{array}{l}\text { Ruptured mycotic } \\
\text { aneurysm } \\
(n=22)\end{array}$ & $\begin{array}{l}\text { ICH secondary to } \\
\text { ischaemic stroke } \\
(n=27)\end{array}$ & $P$ \\
\hline \multicolumn{5}{|l|}{ Timing of $\mathrm{ICH}$ diagnosis } \\
\hline Inaugural diagnosis & $6(32)^{\mathrm{a}}$ & $10(45)^{b}$ & $20(74)$ & 0.01 \\
\hline Diagnosis in the course of IE & $13(68)^{\mathrm{a}}$ & $11(50)^{b}$ & $7(26)$ & 0.01 \\
\hline $\begin{array}{l}\text { Time between IE and ICH } \\
\text { diagnosis (days) }\end{array}$ & $12[6-25]$ & $7[4-21]$ & $3[2-14]$ & 0.2 \\
\hline \multicolumn{5}{|l|}{ Method of ICH diagnosis } \\
\hline Computed tomography & $19(100)$ & $21(95)$ & $27(100)$ & 0.3 \\
\hline $\begin{array}{l}\text { Cerebral magnetic resonance } \\
\text { imaging }\end{array}$ & $7(37)$ & $12(55)$ & $14(52)$ & 0.5 \\
\hline $\begin{array}{l}\text { Catheter-based cerebral } \\
\text { angiography }\end{array}$ & $6(32)^{c}$ & $18(82)^{\mathrm{b}}$ & $12(44)$ & 0.003 \\
\hline \multicolumn{5}{|l|}{ Clinical signs } \\
\hline Asymptomatic & $2(11)$ & $5(23)$ & $3(11)$ & 0.4 \\
\hline Paresis or plegia & $5(26)^{c}$ & $7(32)$ & $16(59)$ & 0.04 \\
\hline Aphasia & $2(11)$ & $4(18)$ & $7(26)$ & 0.4 \\
\hline Clonic convulsion & $2(11)$ & $1(5)$ & $1(4)$ & 0.6 \\
\hline Disorientation & $4(21)$ & $2(9)$ & $1(4)$ & 0.2 \\
\hline Visual field deficits & $0(0)$ & $0(0)$ & $2(7)$ & 0.2 \\
\hline Headache & $4(21)$ & $7(32)^{\mathrm{b}}$ & $1(4)$ & 0.03 \\
\hline Ataxia & $0(0)$ & $0(0)$ & $1(4)$ & 0.5 \\
\hline Vigilance reduction & $8(42)$ & $4(18)$ & $6(22)$ & 0.2 \\
\hline Glasgow Coma Scale & $14[10-15]$ & $14[13-15]$ & $15[12-15]$ & 0.4 \\
\hline
\end{tabular}

Table 3 Univariate and multivariable analysis, according to the presence of intracranial cerebral haemorrhage.

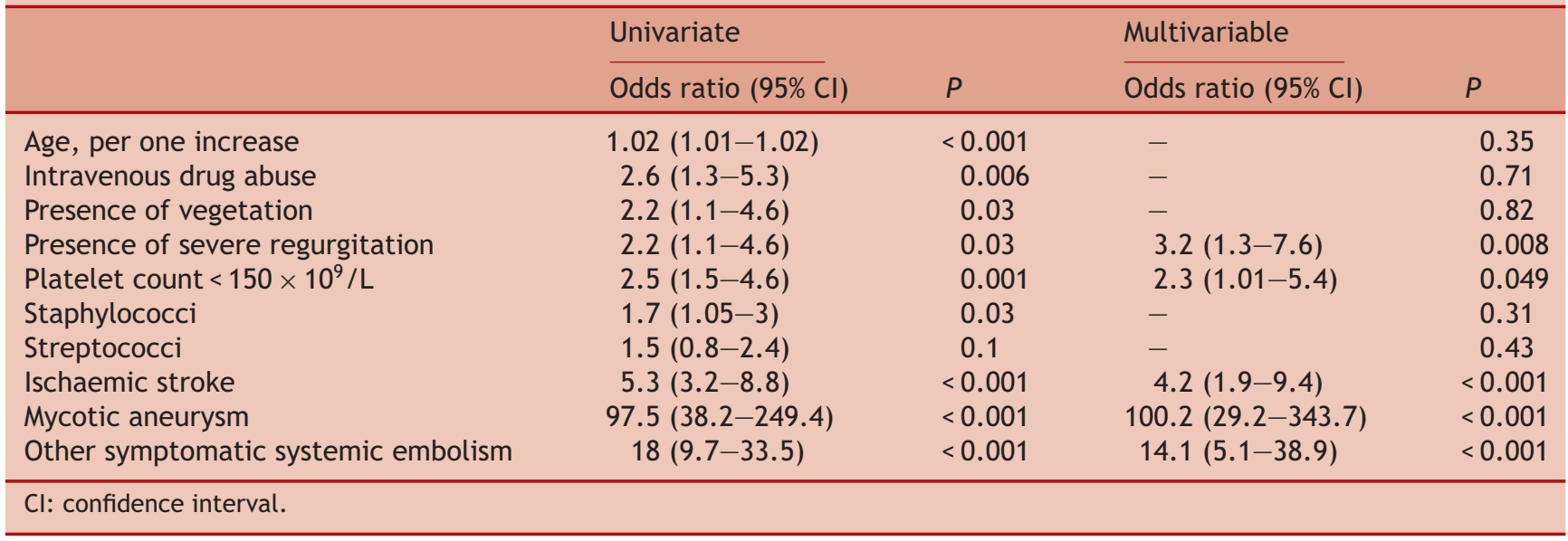

\section{Determinants and management of $\mathrm{ICH}$}

By multivariable analysis (Table 3), five variables were associated with the occurrence of $\mathrm{ICH}$ in patients with leftsided IE: platelet count $<150 \times 10^{9} / \mathrm{L}$; severe regurgitation; cerebral ischaemic embolism; other symptomatic systemic embolism; and presence of mycotic aneurysm.
In patients with an $\mathrm{ICH}, 13$ patients $(19 \%)$ underwent endovascular therapy, consisting of occlusion of ruptured mycotic aneurysm in eight patients and of the affected vessels in five patients with an ICH secondary to ischaemic stroke or undetermined aetiology (Fig. 2). Neurosurgery was performed in another ten patients (15\%), and consisted of 


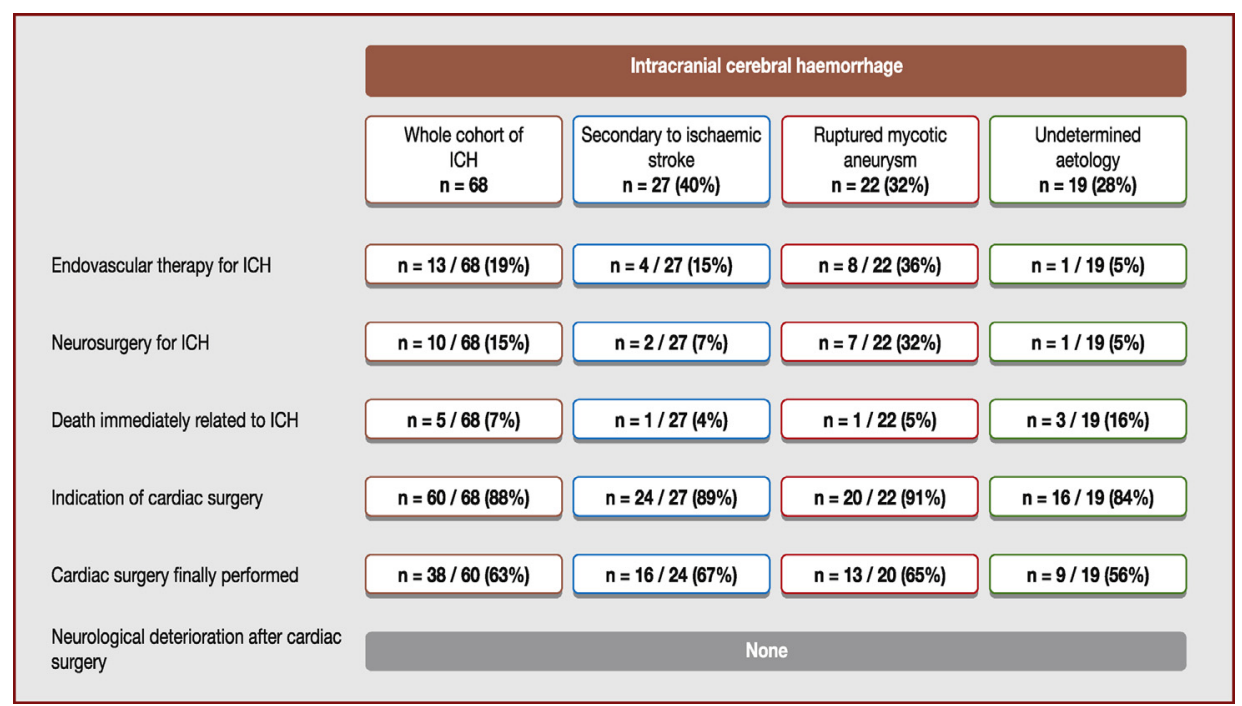

Figure 2. Management and outcomes in patients with intracranial cerebral haemorrhage (ICH) and infective endocarditis.

removal of the underlying cause by clipping the affected vessel/aneurysm in five patients; the other five patients underwent surgery to remove the blood clot and/or treat the mass effect (by standard craniotomy in three patients, and by minimally invasive surgical evacuation in two patients).

\section{Impact of ICH on mortality}

The median follow-up of the whole cohort was 15.9 [5.6-29.8] months; 237 (24.6\%) patients died within a median of 2.3 [0.7-10.4] months after IE diagnosis. Cumulative mortality rates at 1 month, 6 months and 1 year were: $12 \%, 23 \%$ and $23 \%$ in the group with an $\mathrm{ICH} ; 10 \%, 23 \%$ and $26 \%$ in the group with isolated ischaemic stroke; and 7\%, $16 \%$ and $18 \%$ in the group with no neurological vascular complication, respectively. Mortality from any cause during follow-up was not significantly different between the three groups (Fig. 3). The independent predictors of mortality during follow-up were: age (HR 1.02, 95\% Cl 1.01-1.04; $P=0.07)$; periannular lesion (HR 2.5, 95\% Cl 1.6-3.7; $P<0.001$ ); and cardiac surgery for IE during the first year after IE (protector effect, HR 0.3, 95\% Cl 0.17-0.43; $P<0.001$ ).

$\mathrm{ICH}$ was not associated with increased mortality $(P$ not significant). However, when considering the mechanism of $\mathrm{ICH}$, the 1 -year mortality rate was $14 \%, 15 \%$ and $45 \%$ in case of ruptured mycotic aneurysm, haemorrhage after ischaemic stroke and ICH of undetermined aetiology, respectively. Patients with ruptured mycotic aneurysm had a similar risk of death to those with haemorrhage after ischaemic stroke (HR 0.7, 95\% Cl 0.14-2.89; $P=0.6)$. However, patients with an ICH of undetermined aetiology had a higher risk of death than patients with ruptured mycotic aneurysm (HR 4.4, 95\% Cl 1.23-20.39; $P=0.02$ ) and those with haemorrhage after ischaemic stroke (HR $3.1,95 \% \mathrm{Cl}$ 1.01-10.69; $P=0.04$ ) (Fig. 4). Finally, death immediately related to $\mathrm{ICH}$ occurred in three patients with an $\mathrm{ICH}$ of undetermined aetiology, versus one patient in the group with haemorrhage after ischaemic stroke and one patient in the group with ruptured mycotic aneurysm ( $P$ not significant) (Fig. 2).

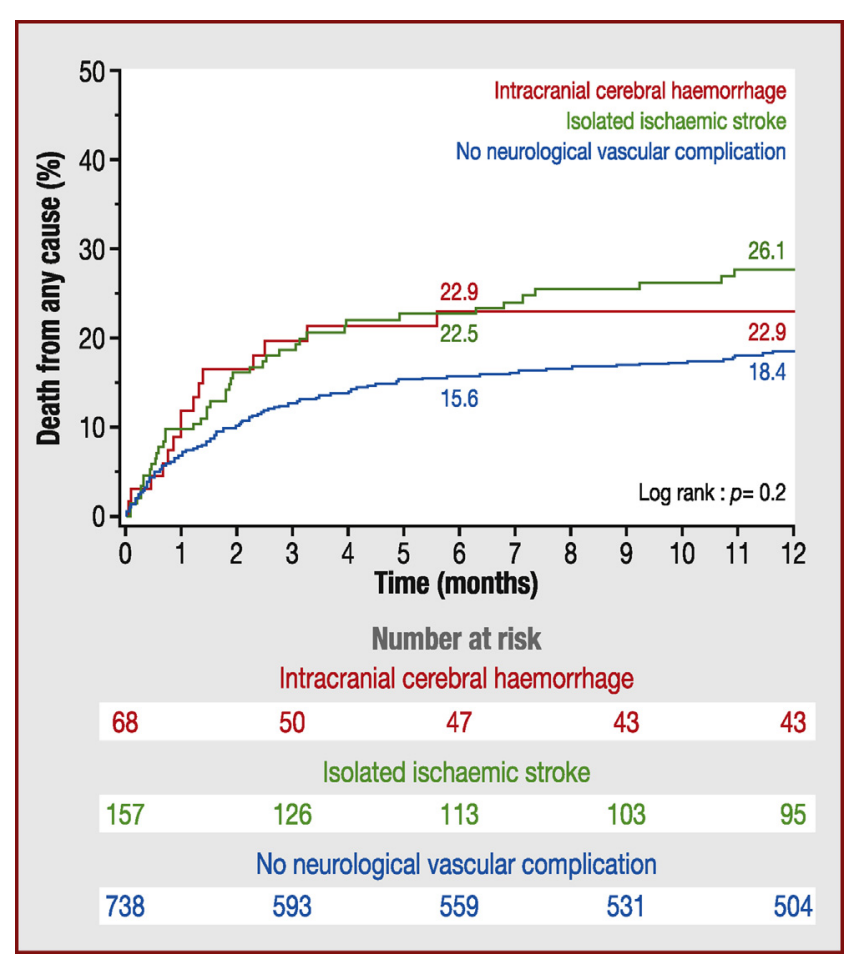

Figure 3. Time-to-event curves for death from any cause in patients with left-sided infective endocarditis complicated by intracranial cerebral haemorrhage or isolated ischaemic stroke, or in patients with no neurological vascular complication.

\section{ICH and cardiac surgery}

Among the 60 patients with an ICH and an indication for cardiac surgery (Fig. 2), 38 underwent cardiac surgery (a median 34 [20-78] days after the ICH). In patients with an indication for cardiac surgery and without death immediately related to $\mathrm{ICH}$, conservative treatment was associated with a higher mortality rate during follow-up compared with cardiac surgery (HR 5.90, 95\% Cl 1.54-28.1; $P=0.01$ ) (Fig. 5). No neurological deterioration occurred in patients who underwent cardiac surgery; especially in the 17 patients 


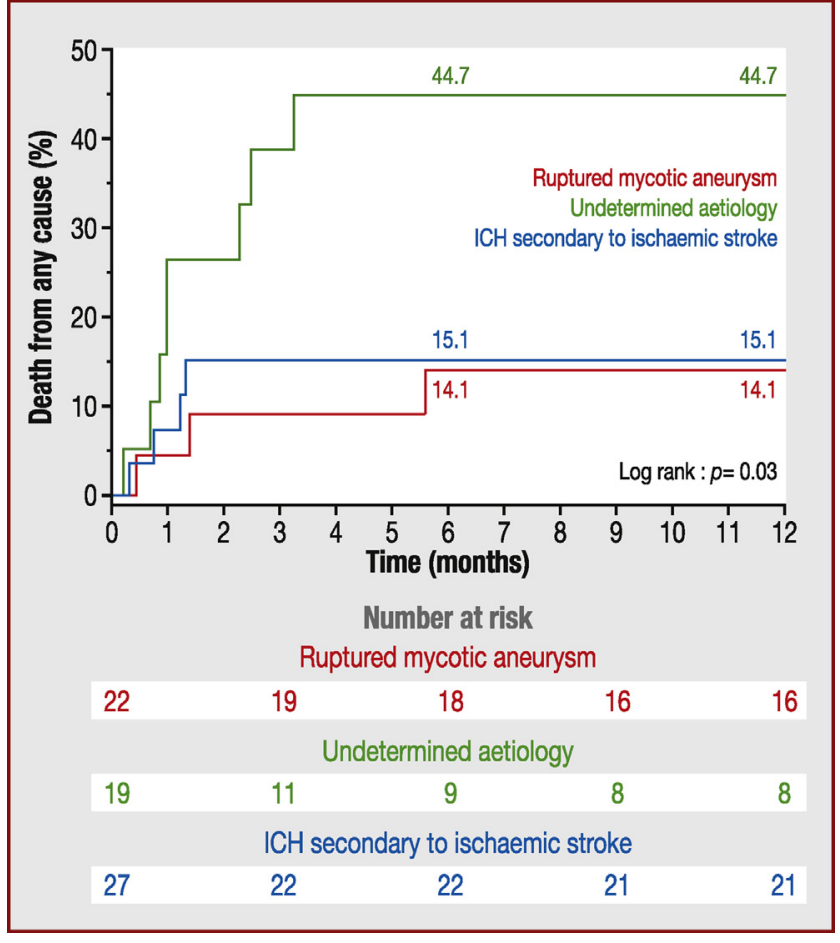

Figure 4. Time-to-event curves for death from any cause in patients with intracranial cerebral haemorrhage $(\mathrm{ICH})$, according to the mechanism of bleeding.

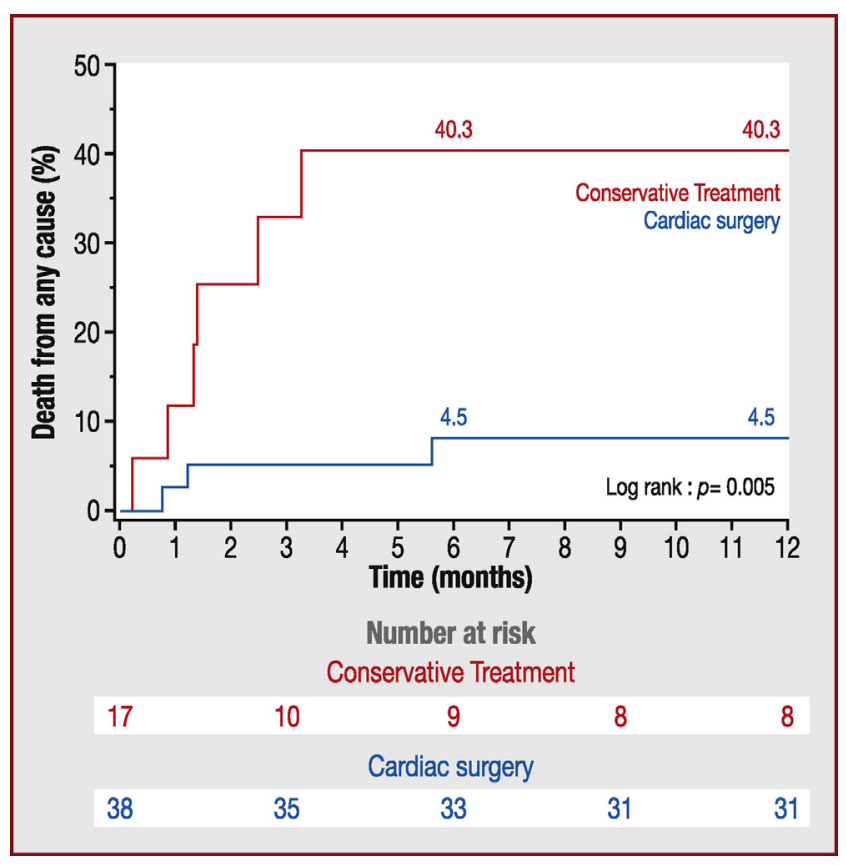

Figure 5. Time-to-event curves for death from any cause in patients with intracranial cerebral haemorrhage, according to conservative treatment or cardiac surgery when indicated.

who underwent cardiac surgery during the first month after the ICH (a median 20 [15-25] days after the ICH).

\section{Discussion}

In this large cohort of patients with left-sided IE, total ICH showed no significant impact on mortality during followup. However, different mechanisms of $\mathrm{ICH}$ may affect the clinical course differently. Patients with an $\mathrm{ICH}$ of undetermined aetiology had a significant excess of mortality compared with those with obvious ruptured mycotic aneurysm or haemorrhage after ischaemic stroke. Five variables were associated with the occurrence of $\mathrm{ICH}$ : platelet count $<150 \times 10^{9} / \mathrm{L}$; severe valve regurgitation; cerebral ischaemic embolism; other symptomatic systemic embolism; and presence of mycotic aneurysm. We observed that cardiac surgery, when indicated, was associated with a better prognosis than conservative treatment in patients with an $\mathrm{ICH}$, and no neurological deterioration occurred in patients who underwent cardiac surgery.

\section{Population characteristics and predictors of ICH}

The incidence of cerebral complications in left-sided IE is high $[4,7,16]$. Embolic aetiology is the most frequent cause [5], but ICH complicates $5-7 \%$ of cases of IE [17]. As in previous studies $[5,6,18,19]$, more staphylococci and a higher incidence and size of vegetation are common trends in neurological vascular complications. In our population, patients with an $\mathrm{ICH}$ were younger and had a higher rate of intravenous drug abuse. For the first time, a specific relationship between ruptured mycotic aneurysm and streptococcal infection was demonstrated. Recently, Monteleone et al. described such an association in a small cohort of patients with mycotic aneurysm (five of seven patients had viridans-group streptococcal infection) [20]. Concerning the potential role of antithrombotic therapy, Garcia et al. showed a higher risk of $\mathrm{ICH}$ in patients with anticoagulant therapy [7]. In our cohort, anticoagulant therapy and platelet inhibition therapy were not associated with an excess of $\mathrm{ICH}$. Outwith the particular context of IE, thrombocytopenia is already associated with haemorrhagic transformation of cerebral infarction and other cerebral haemorrhage $[21,22]$. For the first time, we have found that thrombocytopenia is a predictor of $\mathrm{ICH}$ in patients with leftsided IE.

\section{Various mechanisms, but one spectrum: embolism, "micro"' and "macro"}

It is not surprising that patients with an $\mathrm{ICH}$ had more mycotic aneurysms. However, as described by Thuny et al. [6], several patients with isolated ischaemic stroke also had concomitant unruptured mycotic aneurysm. Moreover, among the 27 patients with mycotic aneurysm and $\mathrm{ICH}$, this vascular lesion was ruptured, and was the origin of the $\mathrm{ICH}$ in only 22 patients. This can be explained by the similarities between the mechanisms of cerebral embolism and bleeding during IE. The mechanism of ischaemic stroke is a migration of a "macro" fragment or the whole vegetation in the cerebral arteries [17]. The mycotic aneurysm arises from "microemboli" to the vasa vasorum, but also secondary to bacterial escape from a septic "macroemboli" 
that has occluded a vessel [23]. As for ICH of undetermined aetiology, it can also result from septic arteritis, with erosion of the vessel wall caused by "microemboli", but without a well-delineated aneurysm $[17,18]$. This confirms the hypothesis of a continuum of arterial injury, ranging from "microemboli"' with pyogenic necrosis and mycotic aneurysm to "macroemboli" in ischaemic stroke. This is concordant with the excess of systemic embolism in patients with an $\mathrm{ICH}$ [5], and promotes the use of accurate imaging (computed tomography and magnetic resonance angiography - and catheter-based angiography, if necessary) for the diagnosis of neurological events.

\section{Impact of ICH and its mechanisms on clinical course}

The presence of an acute neurological complication [5,24], especially an $\mathrm{ICH}$ [7], has been associated with an increased risk of in-hospital mortality in previous studies. Although the 1-month mortality rate was higher in patients with an $\mathrm{ICH}$ than in patients with no neurological vascular complications (12\% versus $7 \%$ ), the difference in mortality during further follow-up was not statistically significant. This result is concordant with the study by Wilbring et al. in a cohort of 495 patients operated on for left-sided IE, who also reported that a preoperative neurological event was a predictor of in-hospital mortality, but was not a predictor of mortality during further follow-up [24]. In a large cohort of 2523 surgical cases of IE, Eishi et al. found no higher mortality rate in patients with cerebral complications compared with those without, and in patients with cerebral haemorrhage compared with those with a cerebral infarction [25].

The impact should also be seen in relation to the mechanism of $\mathrm{ICH}$. Undetermined aetiology was associated with a significant higher rate of death compared with $\mathrm{ICH}$ secondary to obvious ruptured mycotic aneurysm or ischaemic stroke. In addition, diagnostic and therapeutic interventions remain difficult to perform in this subgroup of patients with necrotic vessel [18].

\section{$\mathrm{ICH}$ and cardiac surgery}

$\mathrm{ICH}$ is the most debated cerebral complication in terms of management of IE and the risk of neurological deterioration during cardiac surgery [17]. The recent European Society of Cardiology guidelines recommend that, after $\mathrm{ICH}$, surgery should generally be postponed for $\geq 1$ month [1]. An interesting observation in our study was that conservative treatment when surgery was indicated was dramatically associated with an excess of mortality, while no neurological deterioration was observed when surgery was performed, especially when performed early after the $\mathrm{ICH}$ in selected patients. Yoshioka et al. previously reported a low risk of postoperative neurological deterioration resulting from exacerbation of $\mathrm{ICH}$, even in patients with IE who underwent surgery within 2 weeks of ICH onset [26]. The optimal management remains the case-by-case approach by the endocarditis team and neurological specialists, adapted to the mechanism and severity of the $\mathrm{ICH}$, and the possibility of postponing the cardiac surgery. However, the prognostic benefit of cardiac surgery should not be set aside in relation to the management of neurological complications.

\section{Study limitations}

This was a single-centre study based on data collected prospectively, but with a retrospective analysis. Cerebral magnetic resonance imaging and catheter-based cerebral angiography were not performed systematically, and classification of each type of ICH may be dependent on the accuracy of imaging. Cerebral computed tomography had a lower diagnostic value than magnetic resonance imaging for the diagnosis of mycotic aneurysm, and catheter-based cerebral angiography remains the gold standard [23]. Moreover, mycotic aneurysms are sometimes obliterated by the haemorrhages that they produce, so their arteriographic and even pathological demonstration is not always possible [18].

Other neurological complications, such as abscess and meningitis, were not considered. The impact of cardiac surgery in patients with an $\mathrm{ICH}$ should be interpreted with caution in this observational study. Cases selected for surgery may have hidden biases. This study was performed in a reference centre for the treatment of IE, and may not reflect the management and prognosis of $\mathrm{ICH}$ in other centres.

\section{Conclusions}

$\mathrm{ICH}$ is a common complication of left-sided IE. The impact on prognosis is dependent on the mechanism (haemorrhage of undetermined aetiology). We observed a higher mortality rate in the group of patients who had conservative treatment when cardiac surgery was indicated, compared with in those who underwent cardiac surgery.

\section{Funding}

None.

\section{Disclosure of interest}

The authors declare that they have no competing interest.

\section{References}

[1] Habib G, Lancellotti P, Antunes MJ, et al. 2015 ESC Guidelines for the management of infective endocarditis: the task force for the management of infective endocarditis of the European Society of Cardiology (ESC) endorsed by: European Association for Cardio-Thoracic Surgery (EACTS), the European Association of Nuclear Medicine (EANM). Eur Heart J 2015;36:3075-128.

[2] Wang A, Athan E, Pappas PA, et al. Contemporary clinical profile and outcome of prosthetic valve endocarditis. JAMA 2007;297:1354-61.

[3] Murdoch DR, Corey GR, Hoen B, et al. Clinical presentation, etiology, and outcome of infective endocarditis in the 21st century: the International Collaboration on Endocarditis Prospective Cohort Study. Arch Intern Med 2009;169:463-73. 
[4] Duval X, lung B, Klein I, et al. Effect of early cerebral magnetic resonance imaging on clinical decisions in infective endocarditis: a prospective study. Ann Intern Med 2010;152:497-504 [w175].

[5] Heiro M, Nikoskelainen J, Engblom E, Kotilainen E, Marttila R, Kotilainen P. Neurologic manifestations of infective endocarditis: a 17-year experience in a teaching hospital in Finland. Arch Intern Med 2000;160:2781-7.

[6] Thuny F, Avierinos JF, Tribouilloy C, et al. Impact of cerebrovascular complications on mortality and neurologic outcome during infective endocarditis: a prospective multicentre study. Eur Heart J 2007;28:1155-61.

[7] Garcia-Cabrera E, Fernandez-Hidalgo N, Almirante B, et al. Neurological complications of infective endocarditis: risk factors, outcome, and impact of cardiac surgery: a multicenter observational study. Circulation 2013;127:2272-84.

[8] Li JS, Sexton DJ, Mick N, et al. Proposed modifications to the Duke criteria for the diagnosis of infective endocarditis. Clin Infect Dis 2000;30:633-8.

[9] Di Salvo G, Habib G, Pergola V, et al. Echocardiography predicts embolic events in infective endocarditis. J Am Coll Cardiol 2001;37:1069-76.

[10] Lancellotti P, Tribouilloy C, Hagendorff A, et al. Recommendations for the echocardiographic assessment of native valvular regurgitation: an executive summary from the European Association of Cardiovascular Imaging. Eur Heart J Cardiovasc Imaging 2013;14:611-44.

[11] Lancellotti P, Pibarot P, Chambers J, et al. Recommendations for the imaging assessment of prosthetic heart valves: a report from the European Association of Cardiovascular Imaging endorsed by the Chinese Society of Echocardiography, the Interamerican Society of Echocardiography and the Brazilian Department of Cardiovascular Imaging. Eur Heart J Cardiovasc Imaging 2016;17:589-90.

[12] Hemphill JC, Greenberg SM, Anderson CS, et al. Guidelines for the management of spontaneous intracerebral hemorrhage: a guideline for healthcare professionals from the American Heart Association/American Stroke Association. Stroke 2015;46:2032-60.

[13] Broderick JP, Adams Jr HP, Barsan W, et al. Guidelines for the management of spontaneous intracerebral hemorrhage: a statement for healthcare professionals from a special writing group of the Stroke Council American Heart Association. Stroke 1999;30:905-15.

[14] Horstkotte D, Follath F, Gutschik E, et al. Guidelines on prevention, diagnosis and treatment of infective endocarditis executive summary; the task force on infective endocarditis of the European society of cardiology. Eur Heart J 2004;25:267-76.
[15] Habib G, Hoen B, Tornos P, et al. Guidelines on the prevention, diagnosis, and treatment of infective endocarditis (new version 2009): the task force on the prevention, diagnosis, and treatment of infective endocarditis of the European Society of Cardiology (ESC). Endorsed by the European Society of Clinical Microbiology and Infectious Diseases (ESCMID) and the International Society of Chemotherapy (ISC) for Infection and Cancer. Eur Heart J 2009;30:2369-413.

[16] Yoshioka D, Sakaguchi T, Yamauchi T, et al. Impact of early surgical treatment on postoperative neurologic outcome for active infective endocarditis complicated by cerebral infarction. Ann Thorac Surg 2012;94:489-95 [Discussion 96].

[17] Derex L, Bonnefoy E, Delahaye F. Impact of stroke on therapeutic decision making in infective endocarditis. J Neurol 2010;257:315-21.

[18] Hart RG, Kagan-Hallet K, Joerns SE. Mechanisms of intracranial hemorrhage in infective endocarditis. Stroke 1987;18:1048-56.

[19] Tornos P, Almirante B, Mirabet S, Permanyer G, Pahissa A, SolerSoler J. Infective endocarditis due to Staphylococcus aureus: deleterious effect of anticoagulant therapy. Arch Intern Med 1999;159:473-5.

[20] Monteleone PP, Shrestha NK, Jacob J, et al. Clinical utility of cerebral angiography in the preoperative assessment of endocarditis. Vasc Med 2014;19:500-6.

[21] Zhang J, Yang Y, Sun H, Xing Y. Hemorrhagic transformation after cerebral infarction: current concepts and challenges. Ann Transl Med 2014;2:81.

[22] Neunert C, Noroozi N, Norman G, et al. Severe bleeding events in adults and children with primary immune thrombocytopenia: a systematic review. J Thromb Haemost 2015;13: 457-64.

[23] Peters PJ, Harrison T, Lennox JL. A dangerous dilemma: management of infectious intracranial aneurysms complicating endocarditis. Lancet Infect Dis 2006;6:742-8.

[24] Wilbring M, Irmscher L, Alexiou K, Matschke K, Tugtekin SM. The impact of preoperative neurological events in patients suffering from native infective valve endocarditis. Interact Cardiovasc Thorac Surg 2014;18:740-7.

[25] Eishi K, Kawazoe K, Kuriyama Y, Kitoh Y, Kawashima Y, Omae T. Surgical management of infective endocarditis associated with cerebral complications. Multi-center retrospective study in Japan. J Thorac Cardiovasc Surg 1995;110: 1745-55.

[26] Yoshioka D, Toda K, Sakaguchi T, et al. Valve surgery in active endocarditis patients complicated by intracranial haemorrhage: the influence of the timing of surgery on neurological outcomes. Eur J Cardiothorac Surg 2014;45:1082-8. 